Andrej

Justinek

Izpitni center

za voznike

motornih vozil

\title{
VZGOJA IN IZOBRAŽEVANJE VOZNIKOV
}

T

lehnični vidiki izboljševanja cestnoprometne varnosti se že velikokrat približujejo svojim mejam. Tudi prometna zakonodaja ima omejeno možnost prispevka $k$ večji prometni varnosti. Še vedno pa ostaja široko področje mogočih sprememb pri človeku, vozniku motornih vozil. Iz tega izhaja osredotočenje vseh vzgojnih in izobraževalnih aktivnosti na človeka - ali povedano drugače - na oblikovanje njegovega primernega vedenja $\mathrm{v}$ prometu

\section{Z načrtno vzgojo voznikov bi prispevali $k$ večji varnosti $v$ prometu.} in primernega odnosa do drugih udeležencev $\mathrm{v}$ prometu. Gre za enovit proces, katerega cilj je oblikovanje vzgojenega voznika, ki je pogoj za cestnoprometno varnost.

\section{VOZNIKOVA OSEBNOST}

Osebnost voznika se izraža z njegovim vedenjem. Vsak voznik v cestnem prometu se vede na zanj značilen način. Osebnost voznika lahko opisujemo $\mathrm{z}$ njegovim vedenjem $\mathrm{v}$ prometu. Razen $\mathrm{v}$ posameznih primerih je težko govoriti o posebnih vrstah in tipih (agresiven, podredljiv, dominanten) osebnosti voznikov. Vse preveč je osebnostnih lastnosti, ki so bolj ali manj povezane.

Primerna osebnost voznika vključuje njegovo kompetentnost. Kompetentnost oziroma pristojnost voznika lahko razdelimo na:

- strokovno pristojnost: znanje vožnje motornega vozila $v$ prometu, voznika,
- socialno pristojnost: odgovorno sodelovanje v prometu, - svetovalno pristojnost: odgovorno izkazovanje solidarnosti in pomoči drugim udeležencem v prometu.

Pomembno je voznikovo doživljanje, celostno dojemanje vožnje. Že Boydel (1976) in Jarvis (1989) ugotavljata, da je oseba, ki se veliko nauči na osnovi lastnih izkušenj, praviloma oseba, ki teži k samouresničevanju in razvijanju lastnosti, kot so: samostojnost, samospoštovanje, samozavest, radovednost, odprtost, sposobnost sodelovanja in razmišljajoč odnos do sveta. Vse navedeno so tudi lastnosti, ki jih mora imeti voznikova osebnost.

\section{VOZNIIKOVA VLOGA V PROMETU}

Voznikova vloga $\mathrm{v}$ prometu je varno upravljanje $\mathrm{z}$ vozilom in primerno sodelovanje $\mathrm{z}$ drugimi prometnimi udeleženci. Kvalitetna vožnja je povezana $\mathrm{z}$ voznikovim razmišljanjem o vseh razsežnostih prometa, predvidevanjem načinov njegovega obnašanja in ravnanja ter sprejemanje odločitev $\mathrm{v}$ zvezi $\mathrm{s}$ kasnejšim vedenjem $\mathrm{v}$ prometnih situacijah.

Osnovno vprašanje je, kako bo voznik uporabil svoje sposobnosti, znanja in izkušnje in kdaj bo zaradi napačnih odločitev ali ocen ravnal $\mathrm{v}$ nasprotju $\mathrm{s}$ pravili in načeli za varno vožnjo. Načine vedenja in obnašanja si voznik oblikuje na podlagi množice podobnih situacij v prometu, zato imajo vozniki 
težave $\mathrm{v}$ redkih in popolnoma drugačnih razmerah, kot na primer na poledeneli ali zasneženi cesti, ki zahteva popolnoma drugačen način ravnanja kot suha cesta. Vozniki navadno $\mathrm{v}$ vseh okoliščinah uporabljajo enako ravnanje oziroma vedenje.

Promet je socialno dogajanje, zato mora biti vedenje in ravnanje voznika kooperativno do drugih prometnih udeležencev. Za primerno vedenje in ravnanje je najprej potreben voznikov pozitiven odnos do drugih prometnih udeležencev. Bistvena je voznikova skrb za sodelovanje $z$ drugimi prometnimi udeleženci glede njegovega kulturnega ravnanja in obnašanja ter skrb za prometno varnost glede upravljanja vozila. Vzgojen voznik se zaveda lastnih nezmožnosti in omejenosti in temu tudi prilagodi svojo vožnjo.

Moto vzgojenega voznika je lahko: »V prometu se obnašaj tako, kot bi želel, da se drugi do tebe! « Poleg izkušenih in discipliniranih udeležencev se v promet vključujejo tudi takšni, ki so v vožnji manj spretni. Z nenamernimi napakami povzročajo $\mathrm{v}$ prometnem redu zmedo in nevarne situacije. Voznik se zaradi teh nerednosti ne bo jezil nanje: spomnil se bo svojih pomanjkljivosti in jim skušal solidarno pomagati. Zbral bo vse svoje sile v pripravljenosti, da se ne samo izogne prometni nesreči, marveč tudi vsaki možnosti, da bi nesrečo sam povzročil.

\section{POTREBA PO VZGOJI IN IZOBRAŽEVANJU VOZNIKOV}

Dejavniki prometne varnosti so vozilo, cesta in človek kot voznik. Pomemben dejavnik je tudi družbeno okolje, ki je izvor zakonodajnih pritiskov, s katerimi skuša vzpostaviti prometno varnost. Najpomembnejši dejavnik prometne varnosti je človek, saj znaša njegov delež kar 95 \% (Žlender 1994).

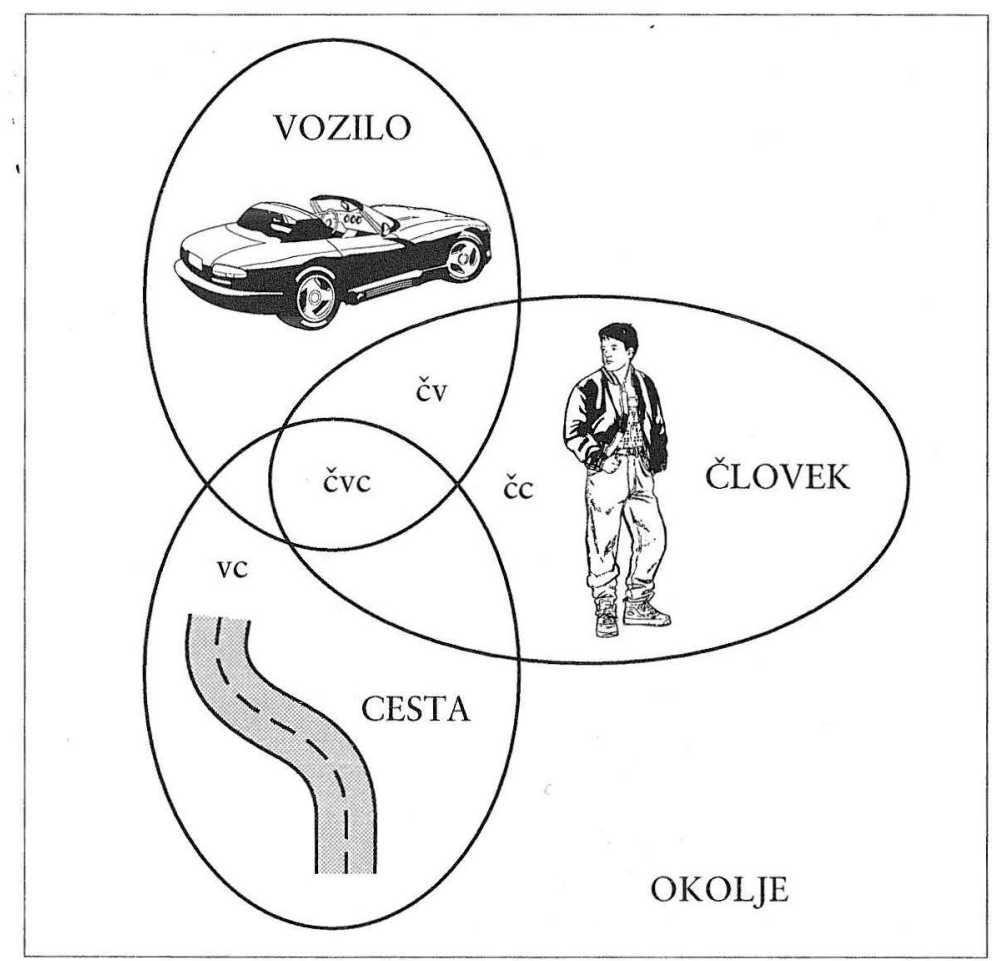

Povezanost dejavnikov prometne varnosti

(po: Rotimu; Žlender 1994)

Primerno vedenje voznikov je določeno predvsem z osebnostnimi lastnostmi, kot so strpnost, empatija, razumevanje, predvidevanje, popravljanje napak, zaupanje vase, primerna samozavest in pripravljenost za izboljšanje vedenja. Vozniki se vedejo različno, pri čemer prevladuje vedenje, ki je odvisno od njihovih interesov, njihovih potreb oziroma motivov in pritiskov okolja (zakoni, prometna pravila).

Interesi in motivi so dejavniki v osebnosti voznika, ki ga privlačijo ali odbijajo od raz-

Za varnost $v$ prometu so najbolj pomembne osebnostne lastnosti voznika. ličnih predmetov, oseb in dejavnosti $\mathrm{v}$ prometnem okolju. Interes voznika lahko opredelimo kot »naklonjenost « ali "nagnjenost « $\mathrm{k}$ določenemu vedenju. Običajno obstaja razkorak med tem, kar voznik želi biti, in tem, kar dejansko je. Čim bolj natančno se bo vo- 
znik zavedal navedenega razkoraka, bolj bo motiviran za spreminjanje lastnega vedenja.

Kako interesi voznika vplivajo na njegovo vedenje v prometu? Pri tem nam je v pomoč definicija Knowlesa (1970), ki uporablja tole shemo:

\section{INTERESI (MOTIVI) + STALIŠČA = VEDENJE}

Primerno vedenje voznika se prične s primernim interesom oziroma motivom. $\mathrm{Ob}$ primernem stališču se razvije njegovo prometno varno vedenje. To je področje vzgoje in izobraževanja voznikov.

\section{OSNOVNI MODEL VEDENIA V CESTNEM PROMETU}

Temelj vedenja v prometu je pravzaprav voznikovo razmišljanje o vožnji. Jaspers govori o treh glavnih izvorih razmišljanja: to so »čudenje, dvom in pretresenost « (Jaspers; v: Kaufmann 1994). Če njegovo presojanje prenesemo na področje prometa, bi lahko rekli, da bo voznik v celoti dojel vso kompleksnost vožnje, če se bo znal čuditi logiki in dejstvom vožnje, kar pomeni, da bo znal tudi podvomiti o že znanih dejstvih o vožnji in pogojih zanjo. To naj bi ga vodilo v novo

\section{Varno}

vedenje voznika

oblikujejo šele izkušnje. razmišljanje o vožnji.

Oblikovanje modela vedenja poteka po naslednjih stopnjah:

- kontekst, spoznanje vsebine vožnje, ki je opredeljena $\mathrm{v}$ sintagmi "primerne (skrbne, pametne, kooperativne) vožnje«;

- izkušnja vožnje, ki je lahko tudi zgolj zaznava, občutenje, predstava o vožnji. To je raven nevoznikov in bodočih voznikov, vendar posameznikov, ki so na kakršen koli način udeleženi v prometu. Vozniki imajo poleg predstave tudi praktično izkušnjo vožnje, ki daje mnogo širši vpogled v vožnjo; - presoja, kar pomeni premišljevanje, razmi- šljanje o vožnji. To razmišljanje daje povratno informacijo o primernosti vožnje. Voznika navaja $\mathrm{k}$ odločitvam, kakšno naj bo njegovo ravnanje na cesti;

- delovanje v skladu z novimi spoznanji, stališči in odločitvami o prometnem vedenju. To je voznikova nova, drugačna, izboljšana, bolj popolna vožnja.

Vendar oblikovanje modela vedenja v prometu še ni končano: ponovno in ponovno se vozniki vračajo $k$ vsem navedenim elementom in nujno sledi zadnja faza:

- ovrednotenje dosežene primernosti vožnje. Stalno vrednotenje je dogajanje, ki je temelj oblikovanja primernih stališč in primernega vedenja v cestnem prometu.

Osnovni model voznikovega vedenja in ravnanja neposredno pogojuje način njegove vožnje motornega vozila.

\section{VZGOIA ZA PRIMERNO VEDENJE V PROMETU}

Vedenje voznika v cestnem prometu pomeni način, vzorec njegovega sodelovanja $\mathrm{v}$ prometu in je odsev njegovega stališča do prometa. Voznik motornega vozila $\mathrm{v}$ cestnem prometu deluje, postopa in se vede v skladu s svojim stališčem. Vedenje voznika je obenem podvrženo tudi objektivnemu, zunanjemu dejavniku prometa, ki ga oblikujejo prometna pravila in prometna zakonodaja. Voznikovo vedenje ne more in ne sme biti $\mathrm{v}$ bistvenem razkoraku $\mathrm{z}$ zakonodajnimi zahtevami, ki jih določa država kot odgovorna za prometno varnost.

Voznikovo vedenje oblikuje njegovo vožnjo (Webster 1974). Vedenje voznika je odvisno od njegovih predhodnih izkušenj, povezanih s prometom, in od njegovega razmišljanja o prometu.

Vozniku motornega vozila je enako kot nova izkušnja potreben tudi ponovni razmislek o preteklih izkušnjah. Izkušnje same po sebi 
niso niti dobre niti slabe, pomembneje je, kako jih doživlja in vrednoti posameznik. Vožnja ni in ne sme biti rezultat naključja, ampak je stvar voznikove razumske odločitve. Na osnovi predhodnega izkustva in razmišljanja o vožnji nastaja njegovo vedenje, ravnanje in obnašanje na cesti.

Povedano je le splošno vedenje, v katerem lahko interpretiramo najbolj različna vedenja voznikov. Vedenja voznikov so povezana z njihovimi življenjskimi slogi (vsakdanjimi vozniškimi navadami in razvadami) in jih je možno z vzgojo spreminjati. Pomembna so vedenja, ki ohranjajo ali izboljšujejo prometno kulturo in varnost. Vzgojo za omenjena vedenja je treba začeti že dovolj zgodaj, preden nevarna vedenja postanejo navada (Polič 1996).

\section{OBLIKOVANJE MODELA VEDENJA VOZNIKA}

Primeren model vedenja se oblikuje z vzgojo za varno sodelovanje v prometu, ki se prične že v najnežnejši dobi posameznika. Voznikom se model vedenja oblikuje z oblikami dopolnilne vzgoje. Model vedenja voznika je dinamično dogajanje, ki se razvija s stalnim voznikovim sodelovanjem v prometu.

Vedenje voznika je neposredni izraz njegovih vedenjskih namer (obvez sebi ali drugim, da bomo nekaj storili), ki so odvisne od stališč do namere in subjektivnih norm o njeni ustreznosti (Žlender 1996). Stališča temeljijo na prepričanju o verjetnih izidih namere. Subjektivne norme izvirajo iz prepričanj voznika o tem, kaj drugi menijo, da naj bi storil (normativna prepričanja) in motivacije, da se jim podredi. Ti dejavniki skupaj oblikujejo vedenjsko namero in končno vedenjsko spremembo (Žlender 1996, str. 86). Poleg omenjenih dejavnikov je za vedenjsko namero potrebno poznati tudi zaznani nadzor nad nameravanim dejanjem. Voznik mora čutiti, da je pri nameravanem dejanju nadzorovan. Model vedenja bi lahko zapisa-

li v obliki enačbe:

$$
\mathrm{VN}=\mathrm{Su} 1+\mathrm{SNu} 2+\mathrm{Znu} 3
$$

VN je vedenjska namera, $\mathrm{S}$ stališče, $\mathrm{SN}$ subjektivna norma in $\mathrm{ZN}$ zaznani nadzor, " $\mathrm{u}$ " pa predstavlja težo oziroma pomen posameznega dejavnika.

\section{VPLIVI NA VEDENJE VOZNIKOV}

Vedenje voznika vsebuje obstoječe, dejanske načine prometnega vedenja med vožnjo in možne načine vedenja. Področje možnega vedenja lahko delimo na področje varnega vedenja in na področje nevarnega vedenja. Področje možnega vedenja določajo fiziološke, spoznavne, okoliške in nadzorne omejitve voznika (Polič 1996). Okoliške omejitve zadevajo značilnosti okolja, ki neposredno (»fizično zaprta cesta «) ali posredno (»s prometnim znakom omejena hitrost vožnje «) omejujejo voznikovo ravnanje. Nadzorne omejitve zadevajo voznikove odločitve za varno vedenje in ravnanje $\mathrm{v}$ prometu. Okoliške omejitve štejemo za pasivne nosilce varnega vedenja, nadzorne omejitve pa za aktivne.

Na vedenje na cesti vpliva tudi dejstvo, da za varno vedenje voznik ni nagrajen takoj in tudi kazen za nevarno vedenje ni nujna in takojšnja. Marsikatero varno vedenje samo po sebi za voznika ni vedno najbolj ugodno in njegove prednosti niso jasno razvidne. Vozniki tudi ohranjajo nestvaren optimizem glede možnosti, da se bo njim ali drugim prometnim udeležencem, ki so z njimi v stiku, kaj resnega zgodilo. Vozniki menijo, da imajo svojo vožnjo pod nadzorom, zaradi pomanjkanja neposrednih izkušenj pa podcenjujejo možnost nastanka prometne nesreče.

Na voznikovo sprejemanje nevarnih vedenj vpliva še množica drugih dejavnikov, kot so demografski, čustveni, socialni in osebni, ki vplivajo na posameznikovo pojmovanje varnosti in nevarnosti (Furnham 1988).

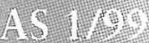


Model vedenja nam skuša razložiti, zakaj se vozniki vedejo tako, kot se, in v kolikšni meri je možno vplivati na njihovo vedenje. Navajamo model varnega vedenja (Polič 1996), po katerem je varno vedenje voznika odvisno od stopnje zaznane ogroženosti lastne varnosti in presoje, da bo varno vedenje učinkovito zmanjševalo ogroženost. Sama zaznava ogroženosti je odvisna od voznikovega vrednotenja varnosti, od njegove občutljivosti za ogroženost ter od zavedanja posledic. Sodba o učinkovitosti določenega vedenja je odvisna od prepričanja, da je le-to učinkovito proti ogroženosti in da njegova korist presega vloženi trud.

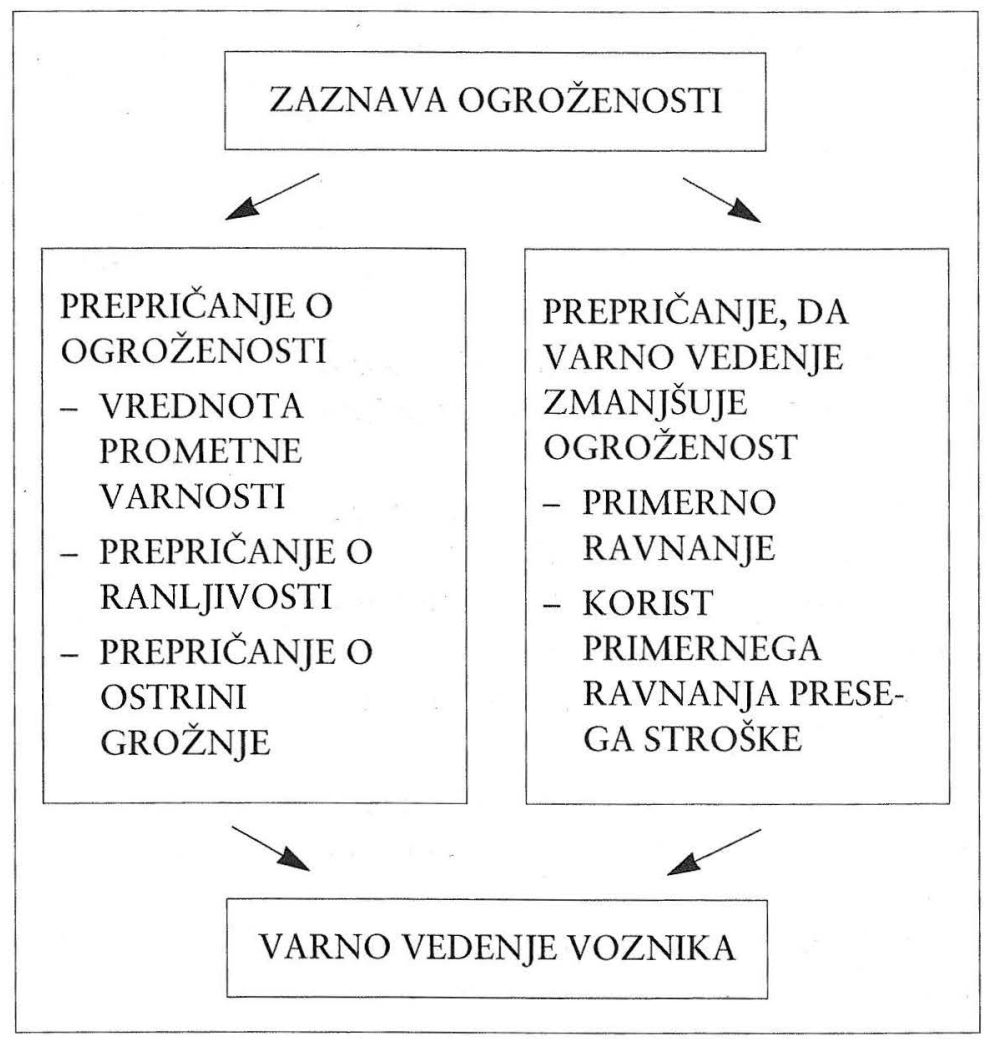

Model varnega vedenja v prometu

(po: Polič 1996)

16 190

Prikazani model vedenja voznika nakazuje del mehanizmov za oblikovanje varnejšega vedenja $\mathrm{v}$ cestnem prometu. $\mathrm{Ob}$ tem lahko navedemo mehanizme učinkovitega vpliva- nja na vedenje voznikov (DiMatteo 1991). Vpliv mora:

- pritegniti pozornost,

- biti sprejemljiv in vreden upoštevanja,

- biti stalen.

Prepričevani voznik mora:

- vpliv povezati s svojimi stališči,

- zaupati pravilnosti vpliva,

- ne sprejemati nasprotnih argumentov.

Učinkovitost vpliva na vedenje je povezana $\mathrm{z}$ voznikovim razmišljanjem in odločanjem o svojem ravnanju, pri tem pa so njegove odločitve povezane $\mathrm{z}$ njegovimi izkušnjami in odvisne od njegovih osebnostnih lastnosti.

Le z večjim številom izkušenj si voznik primerno oblikuje svoje vedenje. Ustvarja si lastne predstave o prometu in lastne modele vedenja $v$ posameznih prometnih situacijah. Oblikovanje modela vedenja brez lastnih izkušenj, samo na podlagi izkušenj drugih, je za voznika izjemno težko. Vzemimo primer, da vsak voznik ve, da lahko za žogo, ki je padla na cesto, priteče otrok. Svoje ravnanje bo prilagodil razmeram na podlagi miselnega vzorca: žoga - otrok. V mnogih primerih voznik sploh ni sposoben predvideti razmer, če nima izkušenj (Žlender 1996). Končno oblikovanje modela vedenja voznika je vedno povezano $\mathrm{z}$ izkušnjami.

$\mathrm{Na}$ voznikovo vedenje vpliva tudi proces razmišljanja, pogleda nazaj in hkrati predvidevanje dogajanja $\mathrm{v}$ prihodnosti (Jarvis 1989). Ponovno vrednotenje enakega prometnega dogajanja poveže morebitno drugačno spoznanje s prejšnjim spoznanjem in preveri veljavnost obstoječega voznikovega vedenja. Rezultat razmišljanja je voznikovo novo spoznanje o prometnem dogajanju, iz katerega sledi novo vedenje in ravnanje na cesti. 


\section{IZOBRAŽEVANJE VOZNIKOV}

Za varno vožnjo je pomembno tudi vozniško znanje. Izobraževalne vsebine, ki so med drugim izhodišča za oblikovanje primernega vedenja voznikov, so zakonsko določene. Izobraževalne vsebine so teoretične in praktične: $s$ prvimi voznik širi svoje teoretično znanje o načinu vožnje, s praktično vožnjo pa izkustveno spoznava varne načine vožnje. Zlasti za voznike začetnike so koristne teoretične osnove, ki so nujne za njihovo osveščanje. Za primer navajamo izobraževalne vsebine, ki jih predpisuje Svet evropske skupnosti in so vključene tudi v slovenski sistem izobraževanja voznikov.

Vozniki v cestnem prometu morajo biti sposobni pokazati poznavanje in pravilno razumevanje naslednjih zadev (Svet Evropske skupnosti 1991):

- pomembnost pozornosti in odnosa do drugih uporabnikov ceste;

- mehanične aspekte, ki so pomembni za varnost na cesti: sposobni morajo biti odkriti najpogostejše okvare, še posebej na sistemih za krmiljenje in zaustavljanje, na pnevmatikah, lučeh in smernikih, žarometih, vzvratnih ogledalih, vetrobranu in brisalcih, izpušnem sistemu in varnostnih pasovih;

- najpomembnejša načela, ki zadevajo upoštevanje varnostne razdalje med vozili, zavorne razdalje in tega, kako se vozilo obnaša na cesti v različnih vremenskih in cestnih razmerah;

- percepcijo, presojo in odločanje, še posebej pa reakcijski čas in tudi spremembe, do katerih pride $\mathrm{v}$ ravnanju voznika zaradi vplivov alkohola, mamil ali zdravil, razpoloženja in utrujenosti;

- specifične dejavnike nevarnosti $\mathrm{v}$ zvezi $\mathrm{z}$ neizkušenostjo drugih uporabnikov ceste in najbolj izpostavljenimi uporabniki, kakor so otroci, pešci, kolesarji in ljudje z okrnjenimi sposobnostmi gibanja;

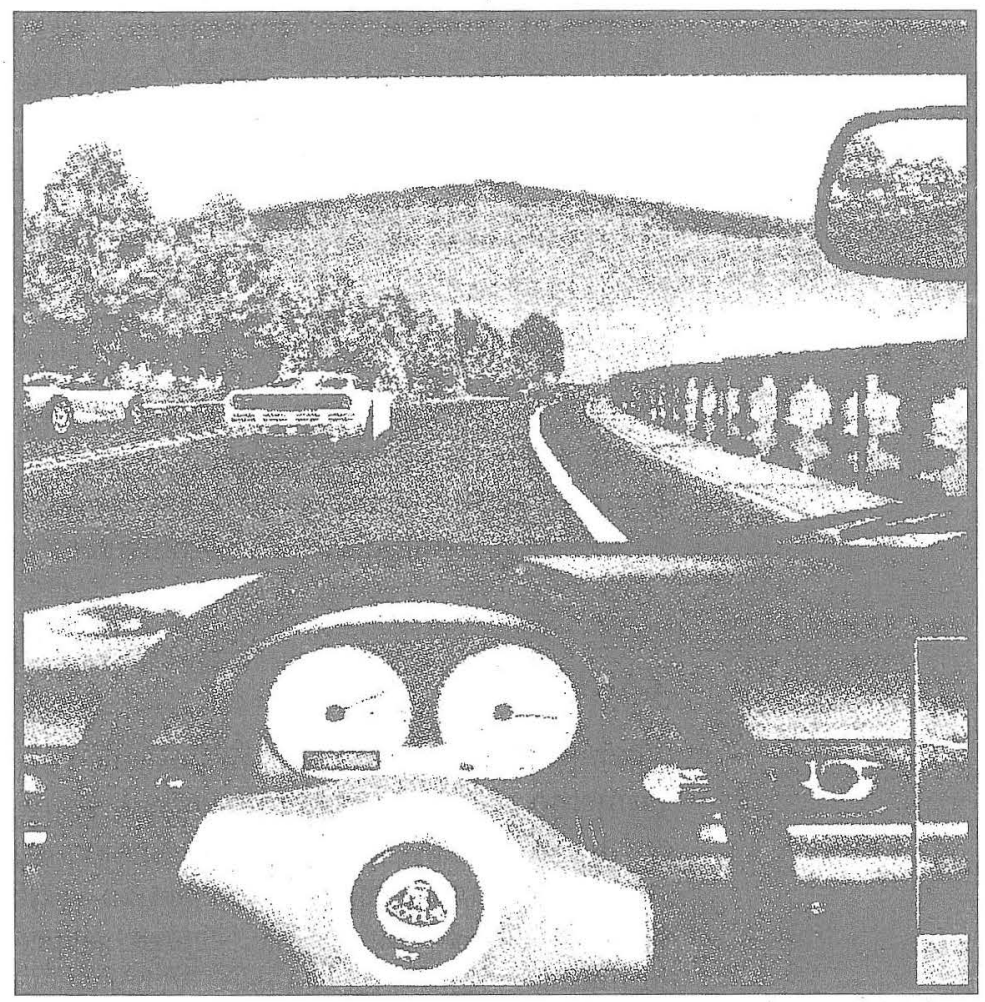

- nevarnosti v zvezi z gibanjem in vožnjo različnih vozil in v zvezi z različnim poljem vidljivosti njihovih voznikov;

- dejavnike nevarnosti pri vožnji zaradi različnih razmer na cesti, še posebej zato, ker se spreminjajo glede na vreme in dnevni oziroma nočni čas;

- značilnosti različnih vrst cest in s tem povezana zakonska določila;

- varnostno opremo vozil in še posebej uporabo varnostnih pasov in varnostne opreme za otroke;

- pravila, ki zadevajo uporabo vozil glede na okolje (pravilno uporabo naprav za zvočno opozarjanje, zmerno porabo goriva, omejitve v zvezi z emisijo polutantov);

- pravila, ki veljajo za cestni promet, še posebej tista, ki zadevajo prometne znake, vključno z označbami, signali, oznakami o prednosti in omejitvah hitrosti;

- pravila, ki zadevajo upravne dokumente, ki so zahtevani za uporabo vozil; 
- splošna pravila, ki opredeljujejo, kako mora voznik ravnati ob nesreči (postavitev opozorilnih pripomočkov in opozarjanje) in kakšni so ukrepi, ki jih lahko stori, da pomaga žrtvam prometne nesreče, če je potrebno;

- varnostne dejavnike v zvezi z vozilom in potniki v njem.

Navedene vsebine zajema program izobraževanja kandidatov za voznike $\mathrm{v}$ avtošolah. Iste vsebine so tudi pravna, zakonska podlaga za varno vožnjo v cestnem prometu.

\section{ZAKLJUČEK}

Voznikovi motivi, ki imajo za posledico neprimerno vedenje in tvegano vožnjo, so različni. Med vsemi motivi je hitrost na prvem mestu. Najpreprostejša motivacija za večjo hitrost je krajši čas vožnje, čeprav se prihranki navadno precenjujejo. $\mathrm{V}$ splošnem vozniki kažejo očitno nepripravljenost, da bi zmanjšali hitrost vožnje na želeno. Vozniki prehitevajo počasnejša vozila, tudi če morajo takoj, ko končajo prehitevati, ustaviti pri rdeči luči semaforja. Hitrost pa hkrati omogoča zadovoljevanje

Prehitra in tvegana vožnja je pogosto kompenzacija za življenjske neuspehe. drugih posebnih motivov. Zanimivo vprašanje je pojem "nagnjenost $\mathrm{k}$ nesreči «. Pojem izhaja iz ugotovitev, da imajo nekateri posamezniki nesorazmerno več nesreč kot drugi (Polič 1994). Pri posameznikih naj bi se nagnjenost $\mathrm{k}$ nesrečam pojavljala ne glede na okoliščine, kot nekakšna njihova osebnostna lastnost. Vendar je nagnjenost $\mathrm{v}$ statističnem smislu sicer očitno dejstvo, ni pa možno najti razlogov za te razlike v osebnostnih lastnostih posameznikov. Mc Guire (1976) trdi, da so določeni ljudje nagnjeni $\mathrm{k}$ nesrečam, toda včasih le za krajši čas (Polič 1994). Reason (1974) zaključuje, da je seznam osebnostnih lastnosti, ki so povezane s to nagnjenostjo, tako obsežen in raznolik, da nikakor ne gre za enoten tip posameznika, nagnjenega $k$ nesrečam (Polič 1994).

Osebna neprilagojenost in nerešeni življenjski problemi bistveno prispevajo $k$ nevarne$\mathrm{mu}$ vedenju in obnašanju $\mathrm{v}$ prometu. Voznik, ki je kot oseba v življenju neuspešen, želi postati "nekdo" $\mathrm{z}$ »ego izražajočo vožnjo « (Polič 1995), ki se kaže v poudarjanju moči, hitrosti in videza vozila ter $\mathrm{v}$ zanemarjanju varnosti. Kršitelji prometnih pravil kršijo običajno tudi druge družbene norme. Neprimerno vedenje je le ena od pojavnih oblik njihovega neprilagojenega načina življenja. Lahko bi se strinjali s Tillmanom in Hobbsom (Polič 1994), da ljudje vozijo tako, kot živijo. Če so v življenju previdni, strpni in skrbijo za druge, tako tudi vozijo.

\section{LITERATURA}

Angenend, W., Erke, H., Hoffmann, G., Marburger, E. A., Molt, W., Zimmermann, G. (1987). Situationsbezogene Sicherheitskriterien im Strassenverkehr. Bergisch Gladbach, Bundesanstalt fur Strassenwessen.

Bačić, F. in soavtorji (1978). Komentar KZ SFRJ. V: Dežman, Z. (1992). Struktura pojma kaznivega dejanja ogrožanja cestnega prometa. Ljubljana, Pravna fakulteta.

Birkholz, C., Lehman, A. (1992). Sozio-marketing fur Verkehrssicherheit. Bergisch Gladbach, Bundesanstalt fur Strassenwessen.

Boydell, T. (1985). Experiental Learning. V: Manchester Monographs, 5. Shefield City Polytechnich.

Dežman, Z. (1992). Struktura pojma kaznivega dejanja ogrožanja cestnega prometa. Ljubljana, Pravna fakulteta.

Di Matteo, M. R. (1991). The Psychology of Health, Illness and Medical Care. Pacific Grove, Brooks \& Cole.

Direktiva Sveta evropskih skupnosti - 91/439/EEC. Bruselj, 29. julij 1991. Uradni list evropskih skupnosti, št. L 237.

Echterhoff, W. (1992). Erfahrungsbildung von Verkehrsteilnehmern. Bergisch Gladbach, Bundesanstalt fut Strassenwessen.

Frankl, V. E. (1985). Man's Search for Meaning, An Introduction to Logotherapy. New York, Simon and Schuster.

Gerondeu, C. in soavtorji (1992). Die Verkehrssicher- 
heit in der Europaischen Gemeinschaft. Zeitschrift fur Verkehrsicherheit, 38, str. 66 - 93.

Gibson, J. J., Crooks, L. E. (1938). A theoretical fieldanalysis of automobile-driving. V: Žlender, B. (1994). Prometne nesreče. V: Polič (ur.), Psihološki vidiki nesreč. Ljubljana.

Glendon, A. I., McKenna, E. F. (1995). Human Safety and Risk Management. London, Chapman \& Hall.

Grimm, H. G. (1988). Wahrnehmingsbedingungen und sicheres Verhalten in Strassenverkehr (Situationsubergreifende Aspekte). Bergisch Gladbach, Bundesanstalt fur Strassenwessen.

Hornke, L. F. (1991). Socialpsihologisch bedingte Risiken im Strassenverkehr. Bergisch Gladbach, Bundesanstalt fur Strassenwessen.

Inić, M. (1987). Bezbednost drumskog saobraćaja. Beograd, Savremena administracija.

Jarvis, P. (1993). Adult Education and the State. London and New York, Routledge.

Justinek, A. (1995). Filozofija vožnje (permanentno izobraževanje voznikov inštruktorjev). Ljubljana, Srednja šola tehničnih strok in osebnih storitev.

Justinek, D. (1996). Osnove psihologije z načeli etike v cestnem prometu. Ljubljana, Alea.

Knowles, M. S. (1970): The Modern Practice of Adult Education, New York, Association Press.

Kroj, G. (1998). Psyhological Aspects of Driver Improvement. V: Globalna varnost - III. mednarodna konferenca (zbornik referatov).

Kuting, H. J. (1986). Verkehrserziehung in der Primarstufe: Social-kognitive Anforderungen und Konception. Bergisch Gladbach, Bundesanstalt fur Strassenwessen.

Leutzbach, W., Papavasiliou, V. (1988). Wahrnehmungsbedingungen und sicheres Verhalten in Strassenverkehr (Wahrnehmung in konkreten Situationen). Bergisch Gladbach, Bundesanstalt fur Strassenwessen.

Lester, J., Maycock G. (1993). Some aspects of driver training research in the UK. Brussell, »JIDITVA « International Days of Traffic Safety.

Mandić, O. (1971). Sistem i interpretacija prava. V: Dežman, Z. (1992). Struktura pojma kaznivega dejanja ogrožanja cestnega prometa. Ljubljana, Pravna fakulteta.

Murrell, H. (1976). Men and Machines. London, Methuen \& Co.

Naatanen, R., Summala, H. (1976). Road - User Behaviour and Traffic Accidents. V: Žlender, B. (1994). Prometne nesreče. V: Polič (ur.), Psihološki vidiki nesreč. Ljubljana.

Pleterski, T. (1984). Poznavanje motornega vozila in tehnika vožnje. Ljubljana, Avto-moto zveza Slovenije.

Polič, M. (1983). Ljudje v prometu. Ljubljana, Zveza šoferjev in avtomehanikov Slovenije.
Polič, M. (1994). Negotovost nesreč, njihova zaznava in človeško vedenje. V: Polič (ur.), Psihološki vidiki nesreč. Ljubljana, Ministrstvo za obrambo Republike Slovenije.

Polič, M. (1996). Prometna vzgoja. V: Žlender (ur.), Prometna psihologija: Mladi v prometu. Ljubljana, Zveza organizacij za tehnično kulturo Slovenije, Svet za preventivo in vzgojo v cestnem prometu Republike Slovenije.

Rothengatter, T. (1981). Traffic Safety Education for Young Children. Lisse, Sweets \& Zeitlinger.

Ruter, G., Stolp, B., Willmerding, G. (1976). Der Mensch als Fahrzeugfuhrer. Bergisch Gladbach, Bundesanstalt fur Strassenwessen.

Seiffert, R. (1970). Šola dobre vožnje. Ljubljana, ČGP Delo.

Schirrmann, I. (1995). Schuelerarbeitsmappe. Muenchen, Formel S - Fahrlehrer Verlag.

Skupina avtorjev (1983). Psihologija v cestnem prometu s prometno etiko. Ljubljana, Avto-moto zveza Slovenije.

Skupina avtorjev (1991). Sicher fahren in Europa. Bergisch Gladbach, Bundesanstalt fur Strassenwessen.

Skupina avtorjev (1994). Prometne nesreče voznikov s krajšim prometnim stažem. Ljubljana, Ministrstvo za notranje zadeve Republike Slovenije.

Šeparović, Z. (1987). Stradanje u prometu (sigurnost i odgovornost). V: Dežman, Z. (1992). Struktura pojma kaznivega dejanja ogrožanja cestnega prometa. Ljubljana, Pravna fakulteta.

Trstenjak, A. (1968). Hoja za človekom. Celje, Mohorjeva družba.

Usposabljanje kandidatov za voznike motornih vozil v avto šolah (1993). Ljubljana, Ministrstvo za notranje zadeve Republike Slovenije.

Wilde, G. J. (1982). The theory of risk homeostasis: Implications for safety and health. V: Žlender, B. (1994). Prometne nesreče. V: Polič (ur.), Psihološki vidiki nesreč. Ljubljana.

Žlender, B. (1994). Prometne nesreče. V: Polič (ur.), Psihološki vidiki nesreč. Ljubljana, Ministrstvo za obrambo Republike Slovenije. 